\title{
Experimental Research of a Diesel Engine with Electronic Control
}

\author{
Leonard-Iulian Cucu ${ }^{1}$, Ion Copae ${ }^{2}$ \\ Eng., S.A-R City Insurance, Bucharest, Romania ${ }^{1}$ \\ Professor Eng., Department of Military Vehicles and Transportation, Military Technical Academy "Ferdinand I", \\ Bucharest, Romania ${ }^{2}$
}

\begin{abstract}
The paper presents some experimental results related to the operation of an electronically controlled diesel engine that equips a car. The most frequent dynamic regimes during the car tests are highlighted. The statistical analysis of the experimental data is presented. Some dependencies between the quantities related to the operation of the engine in dynamic regime are given and mathematical models are established.
\end{abstract}

Keywords: Diesel engine, common-rail, electronic control, engine load and engine speed.

\section{INTRODUCTION}

The paper focuses on one of the most widely used engines in automobiles today [1,7]. This is the compression ignition engine (Diesel engine), the most controversial energy source on vehicles in recent times, especially after the Volkswagen dispute, which highlighted major deviations from anti-pollution rules during the operation of vehicles. However, Diesel engines currently manufactured meet the requirements of anti-pollution regulations, even if they have become more complex and more expensive. The engines manufactured today have an electronic operation management by being equipped with sensors, actuators and microcontrollers, all of which ensure real-time operation control. In this way, the current diesel engine has become more efficient, more powerful, quieter, more economical and cleaner. A current diesel engine has different electronic control systems, the main ones being: fuel injection control system, supercharged air pressure control system, recirculated gas quantity control system, pollutant control system, fuel control system start-up, air-fuel mixture quality control system, speed control system etc. [2, 8].

\section{EXPERIMENTAL RESEARCH}

The experiments were carried out with a Ford Focus car equipped with a turbocharged diesel engine, a common-rail fuel supply system and a recirculated gas control system. The acquisition of the functional parameters was made using Ford's FoCOM interface and software. From the data obtained, 100 more significant experimental tests were selected for the purposes pursued (marked F1-F100), which mark the frequent load and speed regimes during operation.

Thus, in fig. 1 are presented the instantaneous values of the engine torque $M_{e}$ and of the engine power $P_{e}$, in the graphs being also represented the minimum, average and maximum values of the quantities. The maximum values of torque $(215 \mathrm{Nm})$ and power $(66 \mathrm{~kW})$ in the technical specifications of the engine are also highlighted.
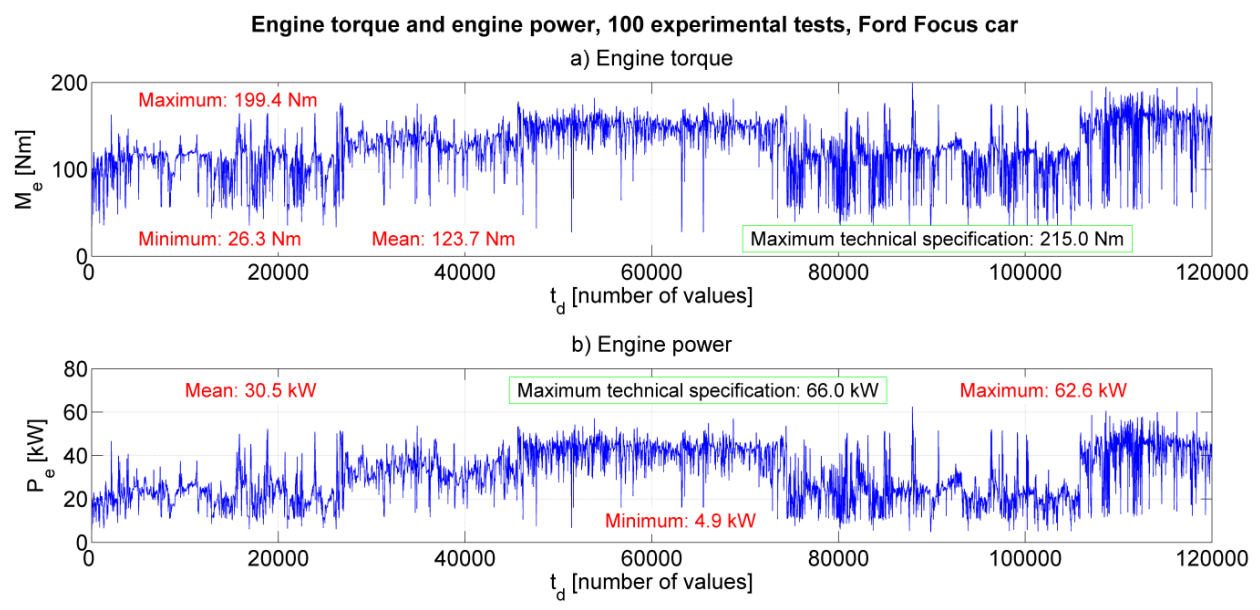

Fig. 1 Engine torque and engine power of the Ford Focus car 


\section{International Advanced Research Journal in Science, Engineering and Technology}

Vol. 8, Issue 3, March 2021

\section{DOI: $10.17148 / I A R J S E T .2021 .8301$}

From fig.1a it results that during the experiments, the engine torque varied in the interval $26.3-199.4 \mathrm{Nm}$, the average on all the tests being of $123.7 \mathrm{Nm}$.

Fig. $1 \mathrm{~b}$ shows that the engine power varied in the range of 4.9-62.6 kW, the average of all tests being $30.5 \mathrm{~kW}$.

Fig. 2 shows the values of load and engine speed $n$, first by the air pressure allowed in the cylinders $p_{a}$. As can be seen from Fig. 2a, all values of the pressure $p_{a}$ are higher than $100 \mathrm{kPa}$, which confirms that the engine is supercharged.

The load and speed of the Diesel engine of the Ford Focus car, 100 experimental tests

a) Intake air pressure (engine load)

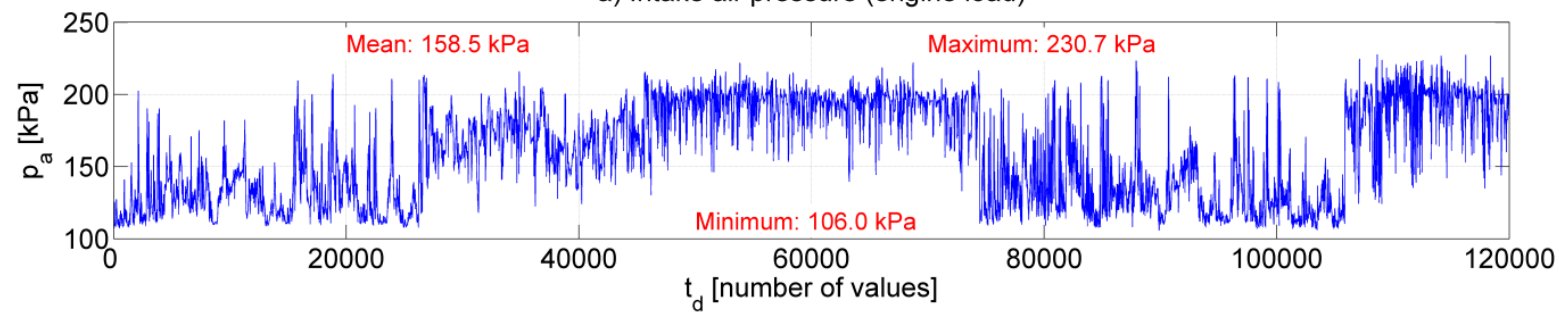

b) Engine speed

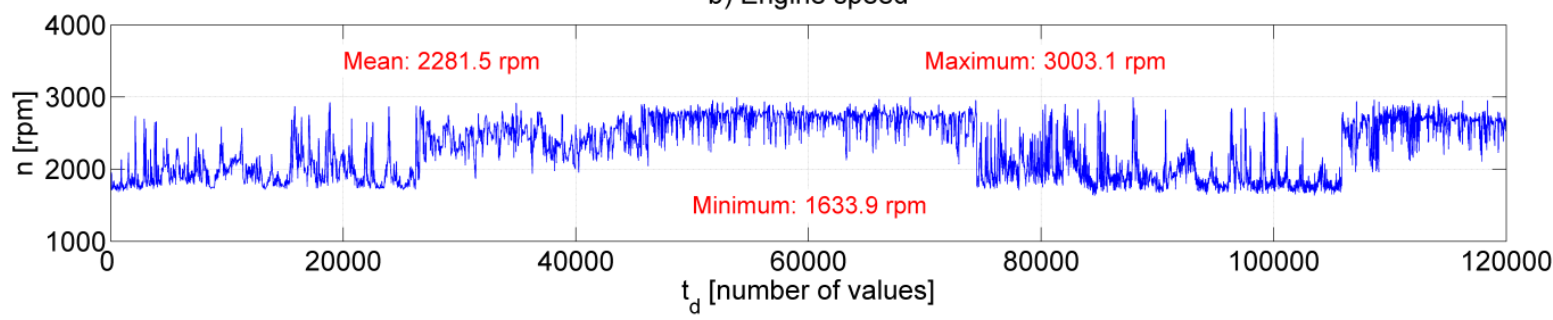

Fig. 2 Air pressure in the intake manifold (engine load) and engine speed formula:

Fig. 3 shows the hourly fuel consumption $C_{h}$ and the cyclic fuel flow $c_{c}$. The cyclic fuel flow is calculated with

$$
c_{c}=\frac{100 C_{h}}{3 n z}
$$

where: $C_{h}[\mathrm{~kg} / \mathrm{h}]$ - hourly fuel consumption of the engine, established experimentally; $n[\mathrm{rpm}]$ - engine speed, established experimentally; $z$ - number of engine cylinders.
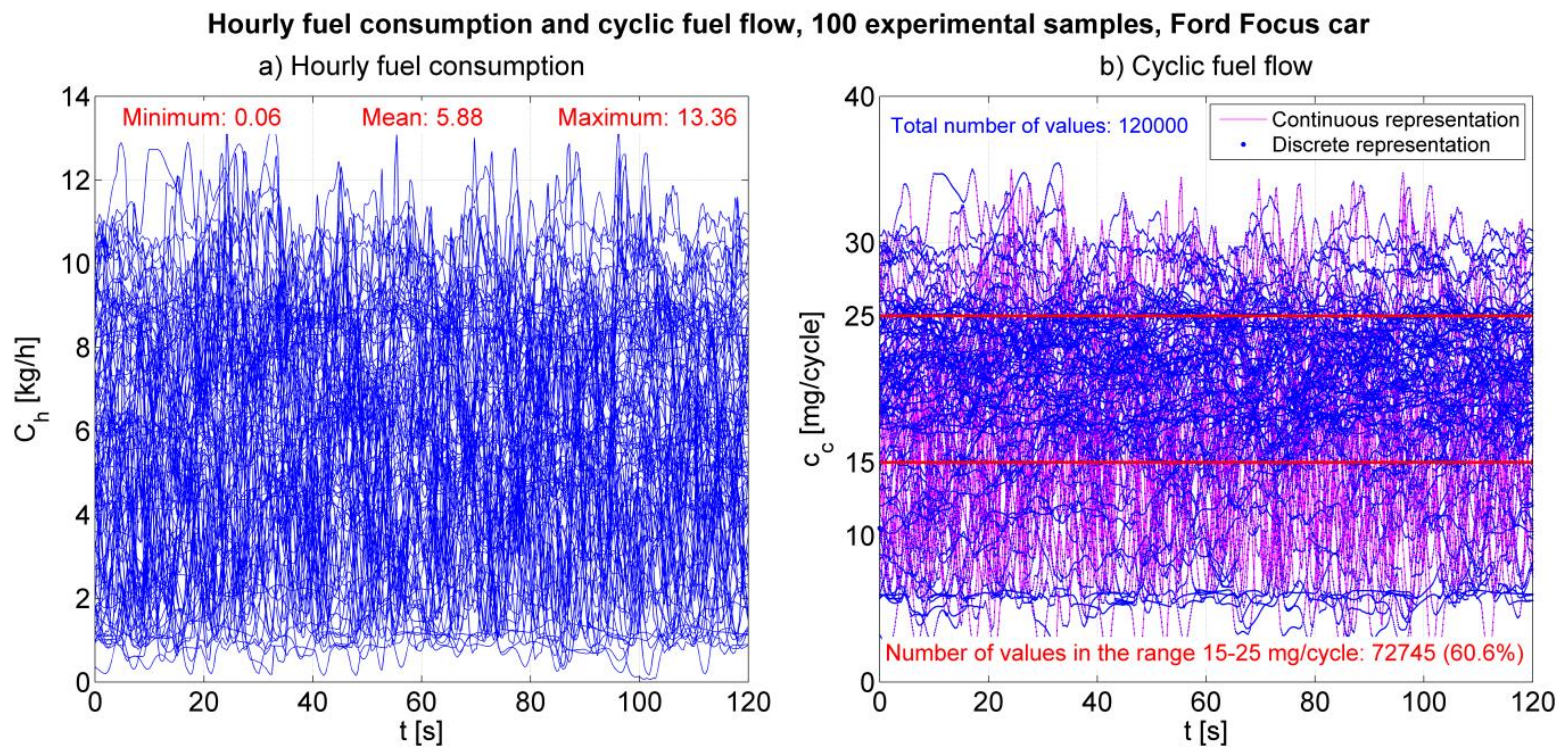

Fig. 3 Hourly fuel consumption and cyclic fuel flow 


\section{International Advanced Research Journal in Science, Engineering and Technology}

Vol. 8, Issue 3, March 2021

\section{DOI: 10.17148/IARJSET.2021.8301}

In fig. 1 and fig. 2 the 100 experimental tests are arranged one after the other, and in fig. 3 they are superimposed; as a result in the first case (fig.1 and fig.2) on the abscissa axis is the discrete time $t_{d}$ [number of values], and in the second case (fig.3) is the continuous time $t$ [s]. In fig.3b there is a continuous representation and a discrete representation of the data, the last being the real one (the experimental data having a discrete character).

The discrete representation in fig. $3 \mathrm{~b}$ allows it to be found more easily that in the interval $15-25 \mathrm{mg} / \mathrm{cycle}$ there are $60.6 \%$ (72745 values) of the total number of values (120000 values).

\section{III.STATISTICAL DATA ANALYSIS}

Based on the experimental data and using the corresponding calculation relations, the usual first order statistical characteristics used can be obtained: mean, variance, standard deviation, minimum value, maximum value, norm 1 , norm 2, infinite norm, etc. Because the experimental data constitute discrete finite series, the computational relations are those related to this character $[3,4,5]$.

Thus, the mean value $m_{x}$, the standard deviation $\sigma_{x}$ and the variance $D_{x}$ are calculated with the expressions, for a finite number of $\mathrm{n}$ data of any size $x$ :

$$
m_{x}=\frac{1}{n} \sum_{i=1}^{n} x_{i} ; \quad \sigma_{x}=\sqrt{\frac{1}{n} \sum_{i=1}^{n}\left(x_{i}-m_{x}\right)^{2}} ; D_{x}=\frac{1}{n} \sum_{i=1}^{n}\left(x_{i}-m_{x}\right)^{2}
$$

The norm 1 or the sum of the absolute values (denoted $L_{1}$ ), the norm 2 or the Euclidean norm (denoted $L_{2}$ ) and the infinite norm or the supreme value (denoted $L_{\infty}$ ) are established with the relations:

$$
\|x\|_{1}=L_{1}=\sum_{i=1}^{n}\left|x_{i}\right| ;\|x\|_{2}=L_{2}=\sqrt{\sum_{i=1}^{n}\left|x_{i}\right|^{2}} ;\|x\|_{\infty}=L_{\infty}=\sup _{i}\left|x_{i}\right|
$$

Another quantity used is the Coefficient Of Variation (COV), which, for a given quantity $x$, is given by the ratio between the standard deviation $\sigma_{x}$ and the mean value $m_{x}$ :

$$
\operatorname{cov}_{x}=\frac{\sigma_{x}}{m_{x}}
$$

Thus, in fig.4a the main statistical quantities for the hourly fuel consumption are shown, and in fig. $4 \mathrm{~b}$ for the engine torque, both at test F92. It is found that at both parameters, the maximum value is the same as the infinite norm.
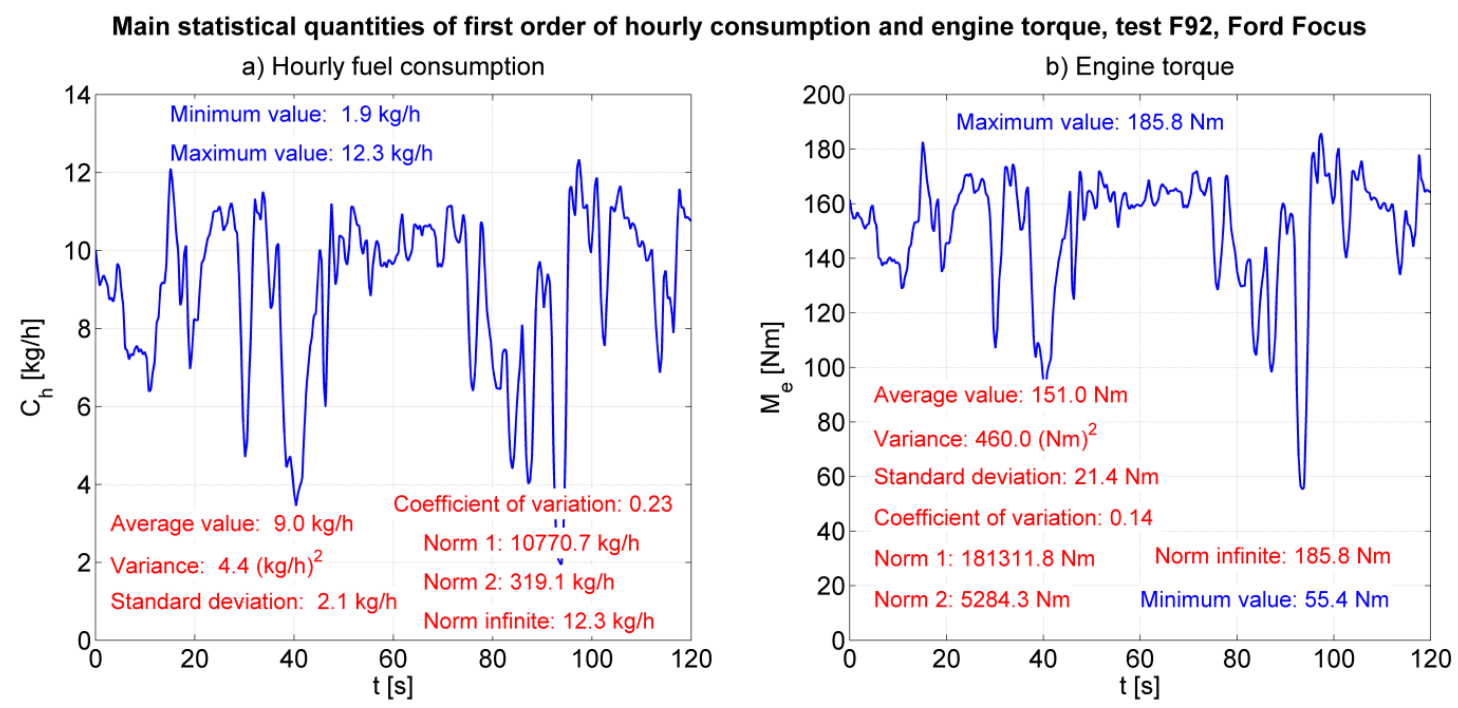

Fig. 4 First-order statistical characteristics of hourly fuel consumption and engine torque 


\section{International Advanced Research Journal in Science, Engineering and Technology}

Vol. 8, Issue 3, March 2021

\section{DOI: 10.17148/IARJSET.2021.8301}

The graphs in fig.5 show the average values on tests of the engine torque $M_{e}$ and of the engine power $P_{e}$. From fig.5a it results that the average values on tests of the engine torque vary in the range 88.6-156.3 Nm, with an average on the set of tests of $123.7 \mathrm{Nm}$. Fig. 5b shows that the average values per tests of engine power vary in the range $17.3-44.1 \mathrm{~kW}$, with an average of all tests of $30.5 \mathrm{~kW}$.

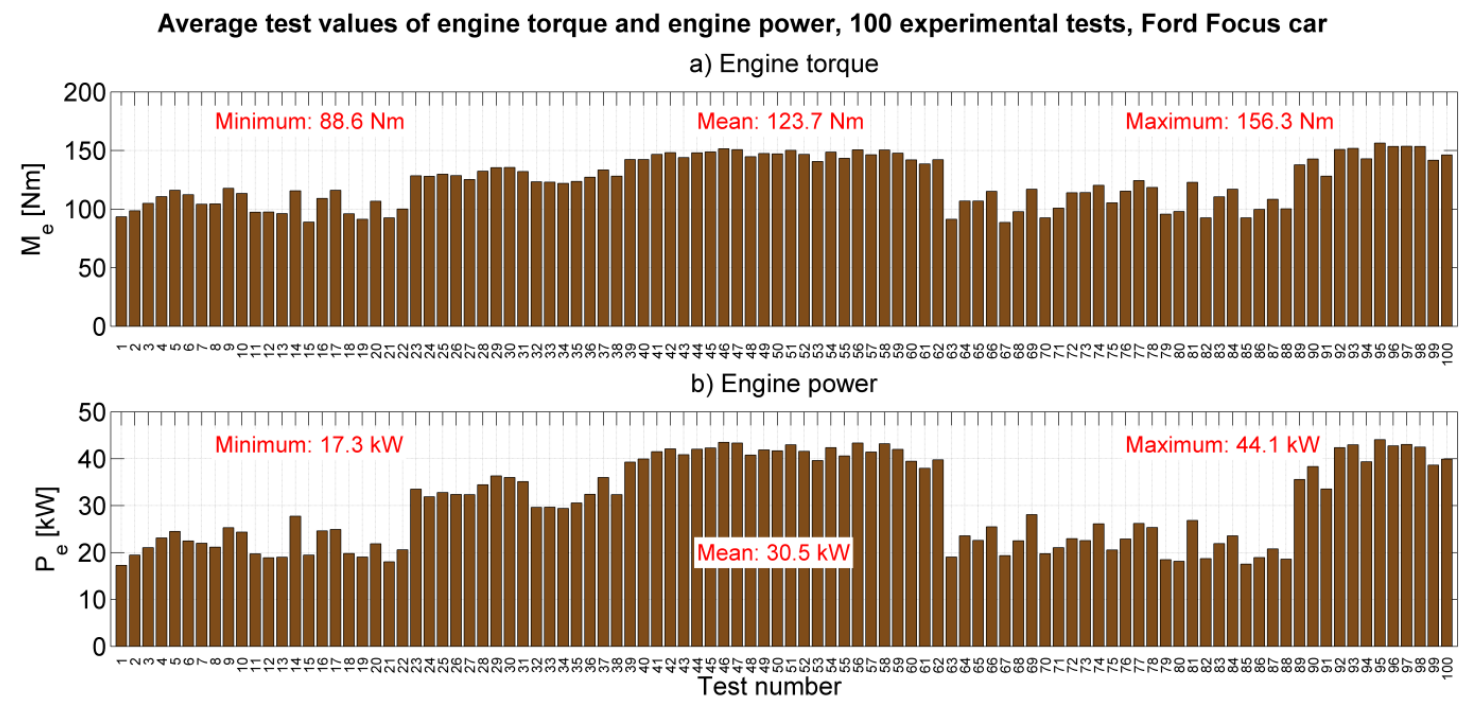

Fig. 5 Mean values on engine torque and engine power tests

The graphs in Fig. 6 show the average values on tests of the effective specific fuel consumption $c_{e}$ and of the effective engine efficiency $\eta_{e}$, established with the expressions $[9,10]$ :

$$
c_{e}=1000 \frac{C_{h}}{P_{e}} ; \eta_{e}=\frac{36 \cdot 10^{5}}{c_{e} Q_{i}}
$$

where $Q_{i}$ represents the lower calorific power of the fuel.

Fig. 6a shows that the average values per test of the effective specific fuel consumption vary in the range 178.6-281.4 $\mathrm{g} /(\mathrm{kWh})$, with an average of all tests of $234.5 \mathrm{~g} /(\mathrm{kWh})$.

Fig. $6 \mathrm{~b}$ shows that the average values per test of the effective engine efficiency vary in the range of 23.6-38.2\%, with an average of all tests of $31.3 \%$.

Average test values of effective specific fuel consumption and effective engine efficiency, 100 tests, Ford Focus car a) Effective specific fuel consumption

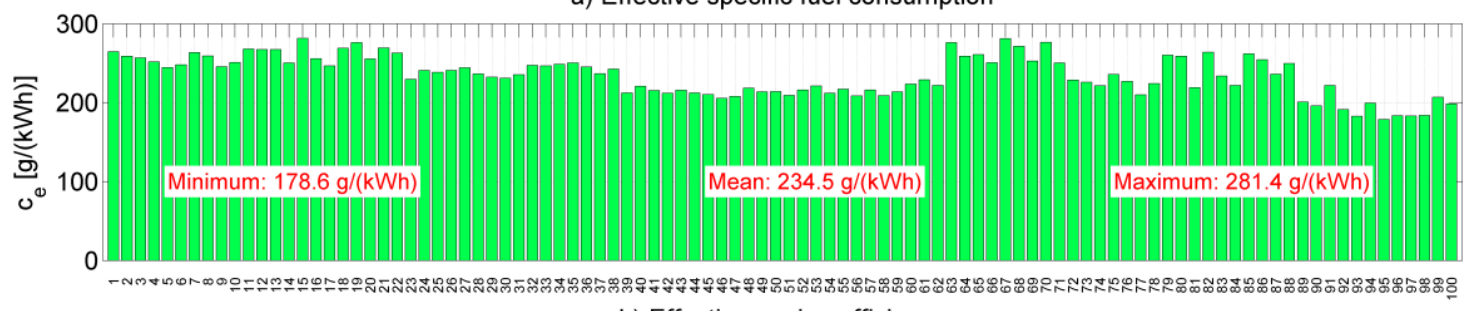

b) Effective engine efficiency

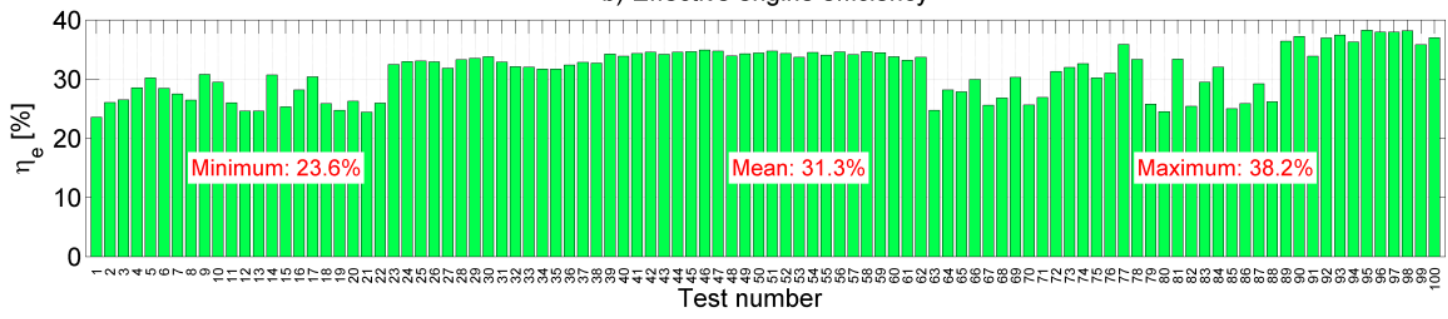

Fig. 6 Average test values of effective specific fuel consumption and effective engine efficiency 


\section{DOI: 10.17148/IARJSET.2021.8301}

Fig. 7 shows the maximum values on tests of the percentage of recirculated gas $\gamma$ and of the angle of inclination of the turbine blades $\alpha$. The percentage of recirculated gas is determined by the relation:

$$
\gamma=\frac{C_{g}}{C_{a}+C_{g}} \cdot 100 \%
$$

where $C_{a}$ represents the hourly air consumption, and $C_{g}$ the amount of recirculated gases.

From Fig.7a it can be deduced that the maximum values on tests of the percentage of recirculated gases vary in the range of $14.8-29 \%$, with an average of $24.3 \%$ on all tests. Fig. $7 \mathrm{~b}$ shows that the maximum values on the tests of the inclination angle of the turbine blades vary in the range of 21.5-54.2 degrees, with an average of all the tests of 43.9 degrees.

Maximum test values of recirculated gas quantity and turbine blade tilt angle, 100 samples, Ford Focus

a) Percentage of recirculated gas quantity

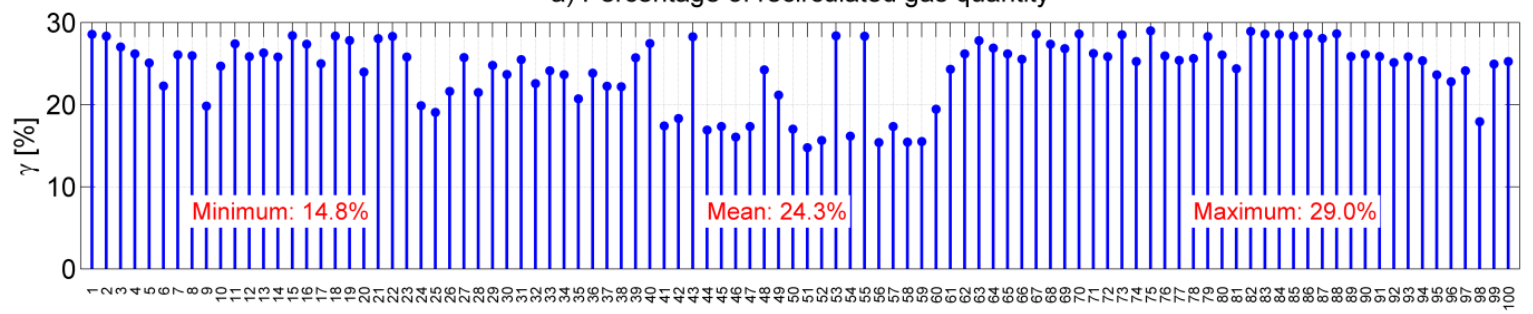

b) Turbine blade tilt angle

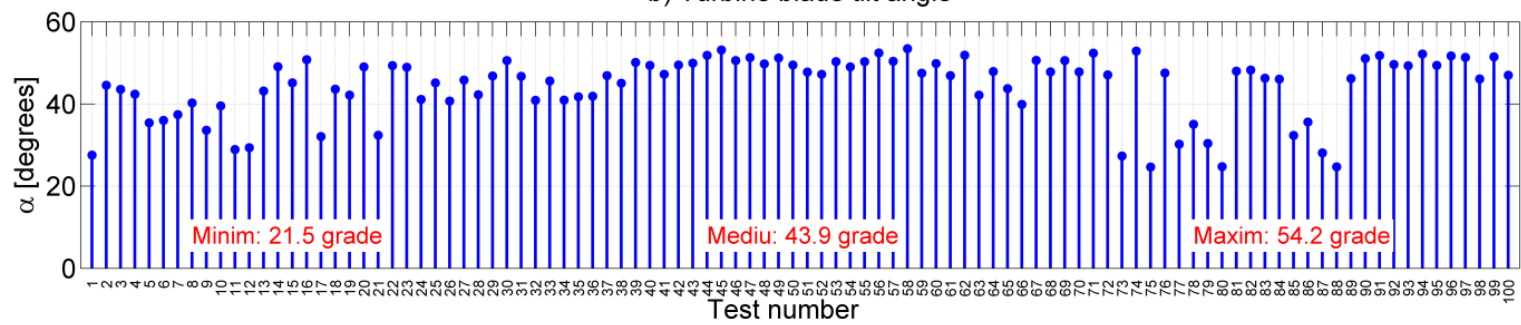

Fig. 7 Maximum values on tests of the amount of recirculated gas and the tilt angle of the turbine blades

Fig. 8 shows the maximum test values of the accelerator pedal position $p$ and engine speed $n$. Fig. 8 a shows that the maximum test values of the accelerator pedal position vary in the range of $55.8-100 \%$, with an average of the total samples of $80.2 \%$.

Maximum test values of the accelerator pedal position and engine speed values, 100 test, Ford Focus car a) Accelerator pedal position

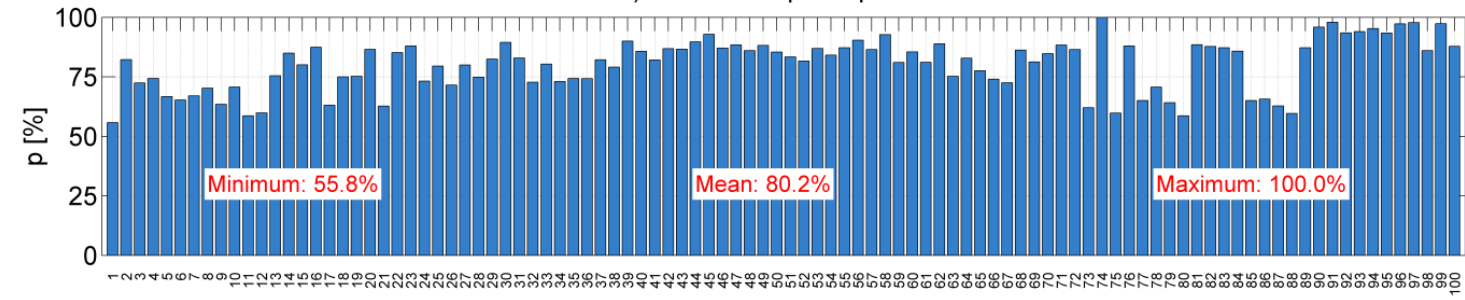

b) Engiine speed

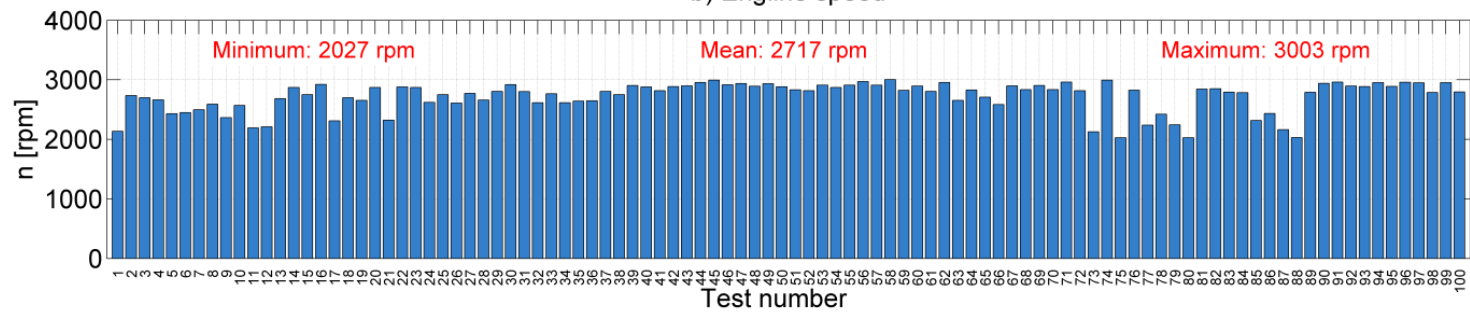

Fig. 8 Maximum values on the tests of the position of the accelerator pedal and the engine speed 


\section{International Advanced Research Journal in Science, Engineering and Technology}

Vol. 8, Issue 3, March 2021

\section{DOI: 10.17148/IARJSET.2021.8301}

Fig. $8 \mathrm{~b}$ shows that the maximum values on tests of engine speed vary in the range 2027-3003 rpm, with an average of all tests of $2717 \mathrm{rpm}$.

\section{IV.FUNCTIONAL DEPENDENCIES}

The existence of electronic control of the diesel engine has as a consequence the supervision of its operation by the onboard computer and as a result it is expected that the functional dependencies between parameters will be more accentuated than in a classic engine. Functional dependencies can also be highlighted with the help of graphs.

For example, Fig. 9 graphically illustrates the functional dependence between the positions of the accelerator pedal $p$, the engine torque $M_{e}$ and the cyclic fuel flow $c_{c}$.

Accelerator pedal position, engine torque and cyclic fuel flow, Ford Focus car

a) Pedal position and engine torque, test F11

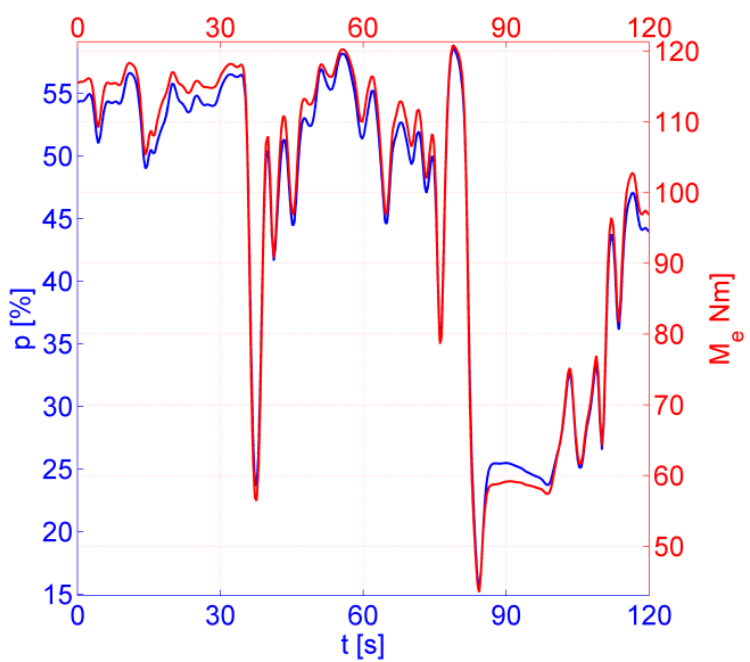

b) Pedal position and cyclic flow, test F24

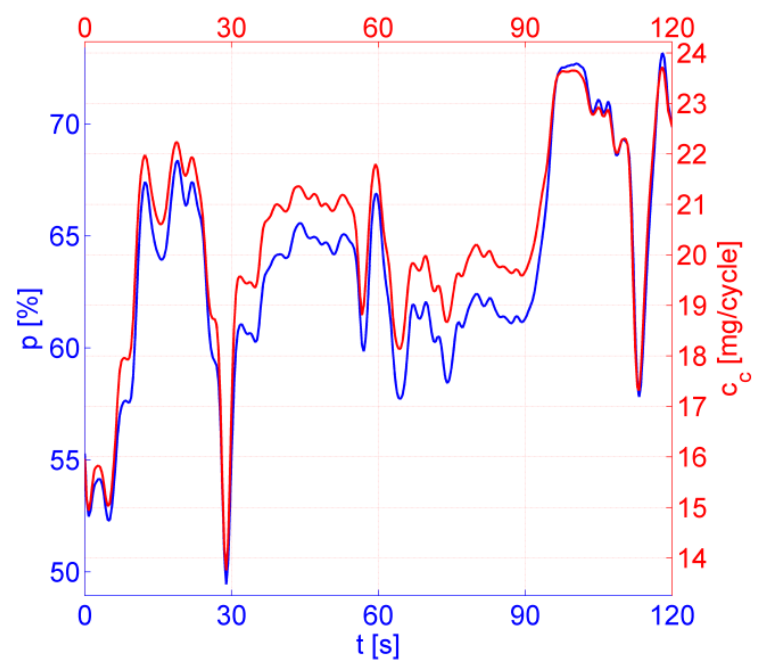

Fig. 9 Dependencies between accelerator pedal position, engine torque and cyclic fuel flow

Similarly, Fig. 10 graphically shows the functional dependence between the position of the accelerator pedal $p$, the intake air pressure $p_{a}$ and the hourly air consumption of the engine $C_{a}$.

Accelerator pedal position, intake air pressure and hourly air consumption, Ford Focus car

a) Pedal position and intake air pressure, test F35

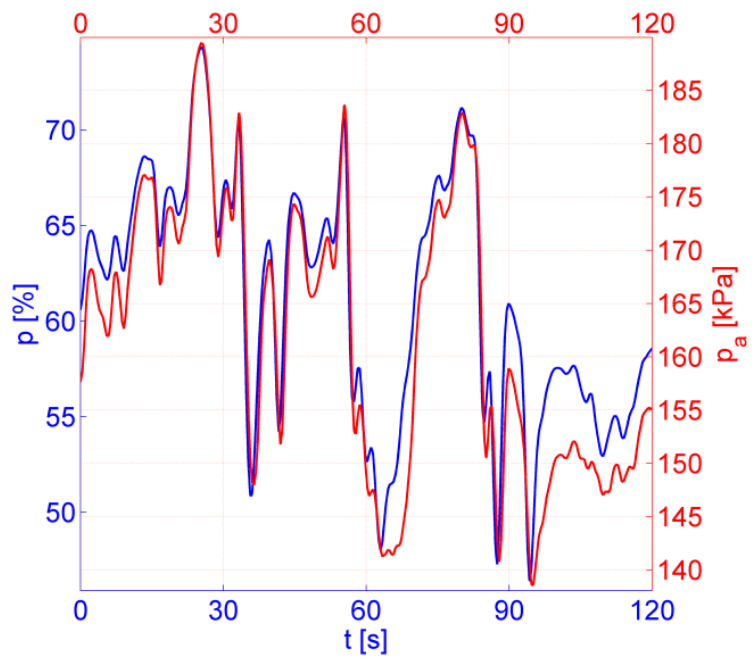

b) Pedal position and hourly air consumption, test F52

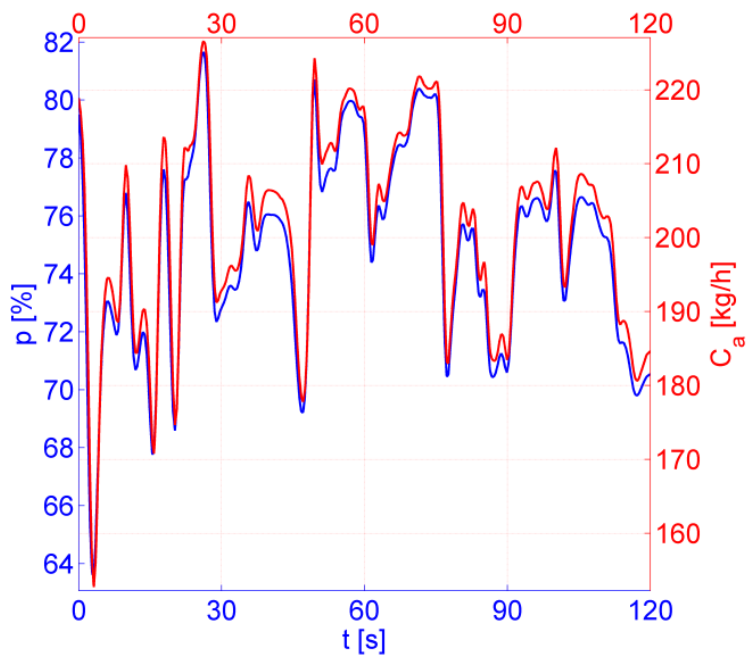

Fig. 10 Dependencies between the accelerator pedal position, intake air pressure and the hourly air consumption

The existence of functional dependencies also allows the deduction of mathematical models of engine operation in dynamic mode and at steady state, in the latter case by establishing static characteristics. 


\section{International Advanced Research Journal in Science, Engineering and Technology}

Vol. 8, Issue 3, March 2021

\section{DOI: $10.17148 / I A R J S E T .2021 .8301$}

\section{MATHEMATICAL MODELS OF ENGINE OPERATION}

Based on experimental data, different mathematical models can be established [6]. For example, for the beginning, mathematical models are established that will highlight the dependencies between the parameters through the average values on their tests, sometimes being visualized also the dependencies between the instantaneous values of the quantities. Later, other mathematical models will be established, but using the instantaneous values of the parameters.

Thus, in fig.11a is shown the dependence between the instantaneous values of the hourly air consumption $C_{a}$, as well as the intake air pressure $p_{a}$, and in fig. $11 \mathrm{~b}$ between the average values on their samples $\left(C_{a m}\right.$ and $\left.p_{a m}\right)$, including the calculation relation (1), both graphs highlighting a direct dependence. Fig. $11 \mathrm{~b}$ also shows the $98 \%$ upper and lower confidence intervals.

Fig. 11b shows the dependence between the average values of the intake air pressure $p_{a m}$ and the hourly air consumption $C_{a m}$ :

$$
C_{a m}=0.00604 p_{a m}^{2}-0.17666 p_{a m}+9.928
$$

Fig. 12 shows the dependencies between the average values of the engine torque $M_{e m}$ and the power $P_{e m}$ and the speed $n_{m}$, and in fig.13 between the average values of the torque and power depending on the position of the accelerator pedal $p_{m}$.

Intake air pressure, hourly air consumption and dependence between them, 100 samples, Ford Focus car a) Consumption depending on pressure - instantaneous values

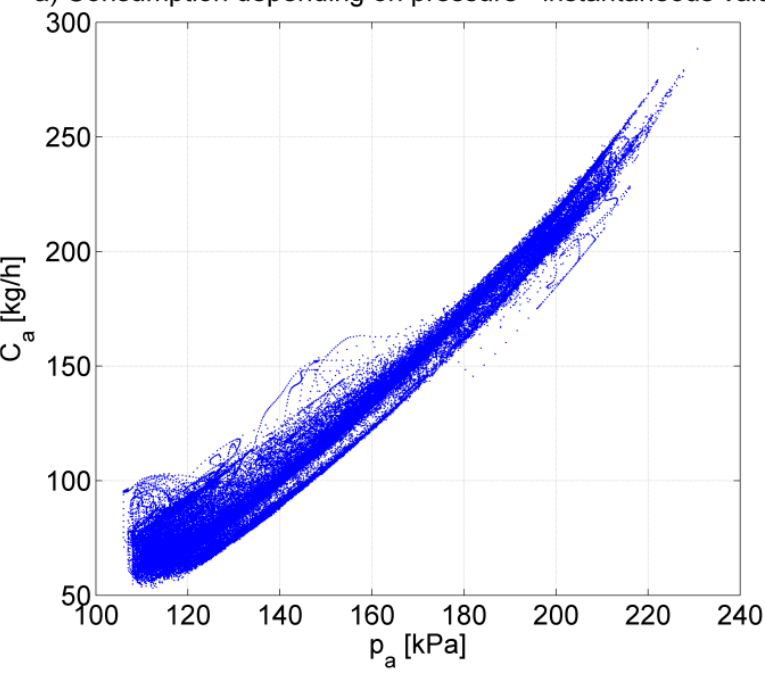

b) Consumption depending on pressure - average values

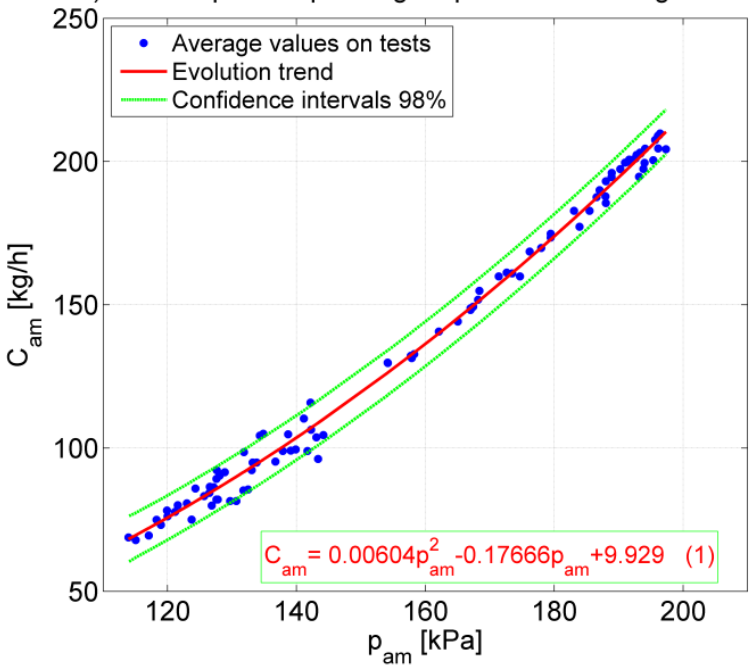

Fig. 11 Mathematical model of form $C_{a m}=\mathrm{f}\left(p_{a m}\right)$

Dependence between the average values on tests of the engine torque and engine power and average values on engine speed tests, 100 experimental tests, Ford Focus car

a) Engine torque depending on engine speed

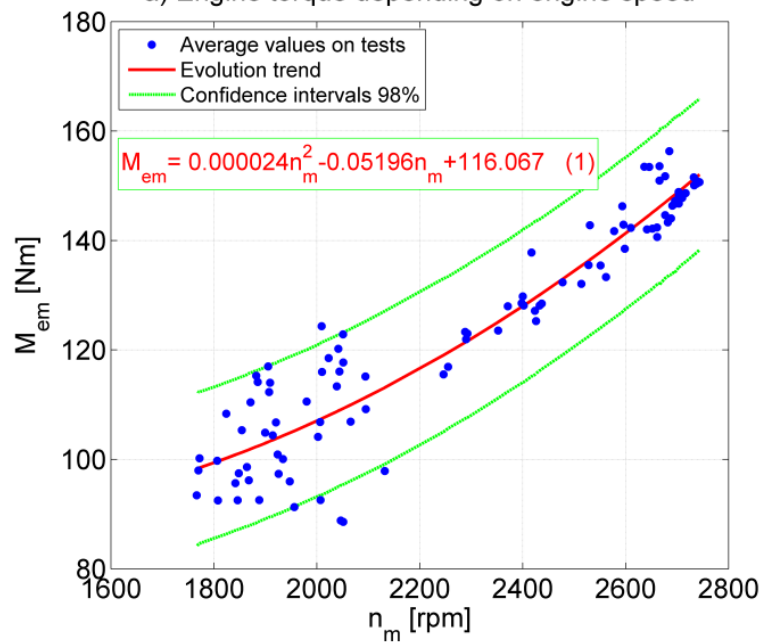

b) Engine power depending on engine speed

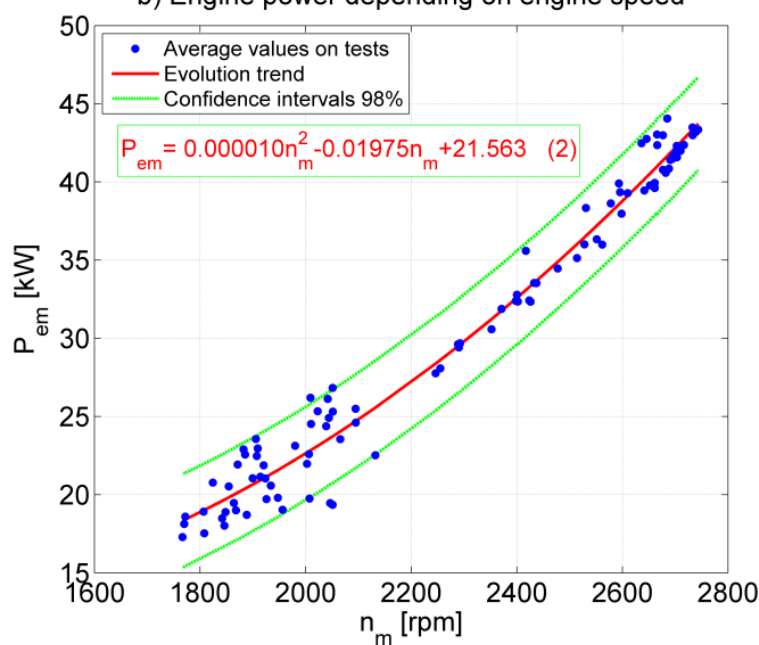

Fig. 12 Mathematical models of form $M_{e m}=\mathrm{f}\left(n_{m}\right)$ și $P_{e m}=\mathrm{f}\left(n_{m}\right)$ 


\section{International Advanced Research Journal in Science, Engineering and Technology}

Vol. 8, Issue 3, March 2021

\section{DOI: 10.17148/IARJSET.2021.8301}

For example, Fig. 12a shows the dependence between the average values of the engine speed $n_{m}$ and the engine torque $M_{e m}$ :

$$
M_{e m}=0.000024 n_{m}^{2}-0.05196 n_{m}+116.067
$$

in the presented graphs being rendered also the other analytical expressions of the mathematical models.
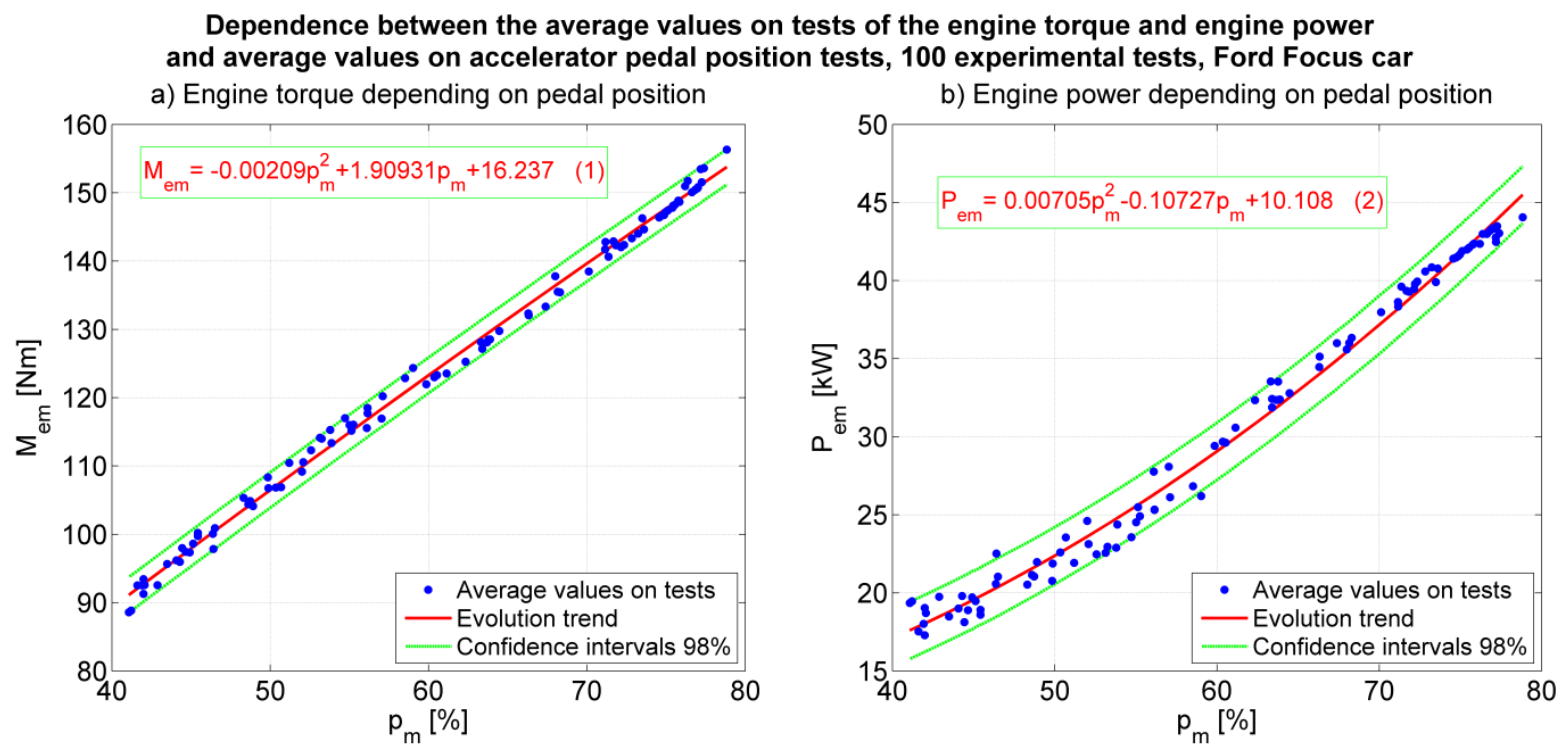

Fig. 13 Mathematical models of form $M_{e m}=\mathrm{f}\left(p_{m}\right)$ și $P_{e m}=\mathrm{f}\left(p_{m}\right)$

Fig. 14 shows the results of establishing a mathematical model that provides the values of the motor torque $M_{e}$ depending on the speed $n$ and the engine load, the last by the position of the accelerator pedal $p$, for all 100 experimental tests; this model is the spatial static characteristic $M_{e}=\mathrm{f}(n, p)$ of the engine. The graph shows the area of commutation of the static characteristic with the analytical expression (1), as well as the 120000 experimental values.

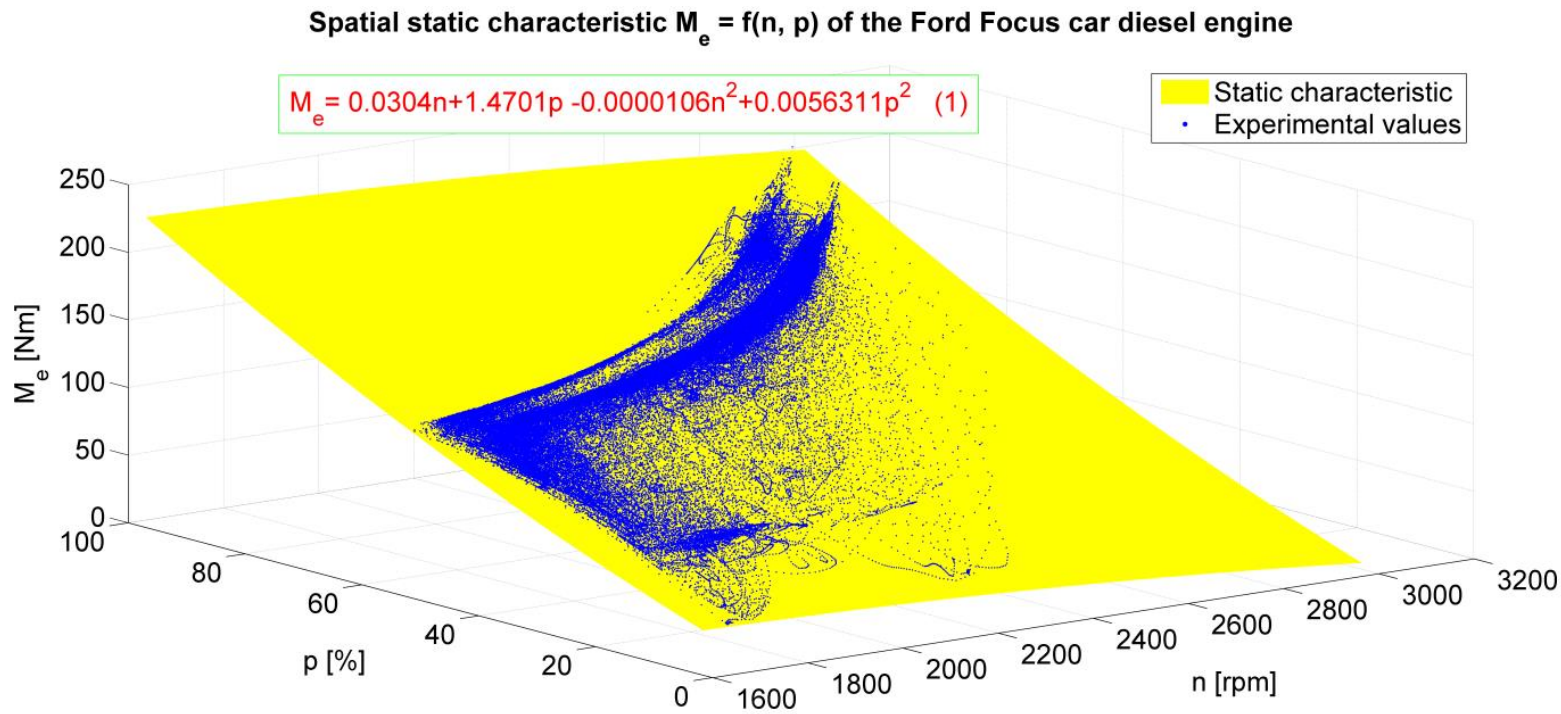

Fig. 14 Mathematical model of form $M_{e}=\mathrm{f}(\mathrm{n}, p)$, spatial representation

Fig. 14 shows the analytical expression of the dependence between the instantaneous values of the engine speed, the position of the accelerator pedal and the engine torque, for all 100 experimental tests:

$$
M_{e}=0.0304 n+1.4701 p-0.0000106 n^{2}+0.0056311 p^{2}
$$




\section{International Advanced Research Journal in Science, Engineering and Technology}

Vol. 8, Issue 3, March 2021

\section{DOI: 10.17148/IARJSET.2021.8301}

similarly other generalized mathematical models can be established.

Fig. 15 shows the same static characteristic of fig. 14, but in contour representation. In this case the rendered curves are of iso-torque $\left(M_{e}=\right.$ const. $)$.

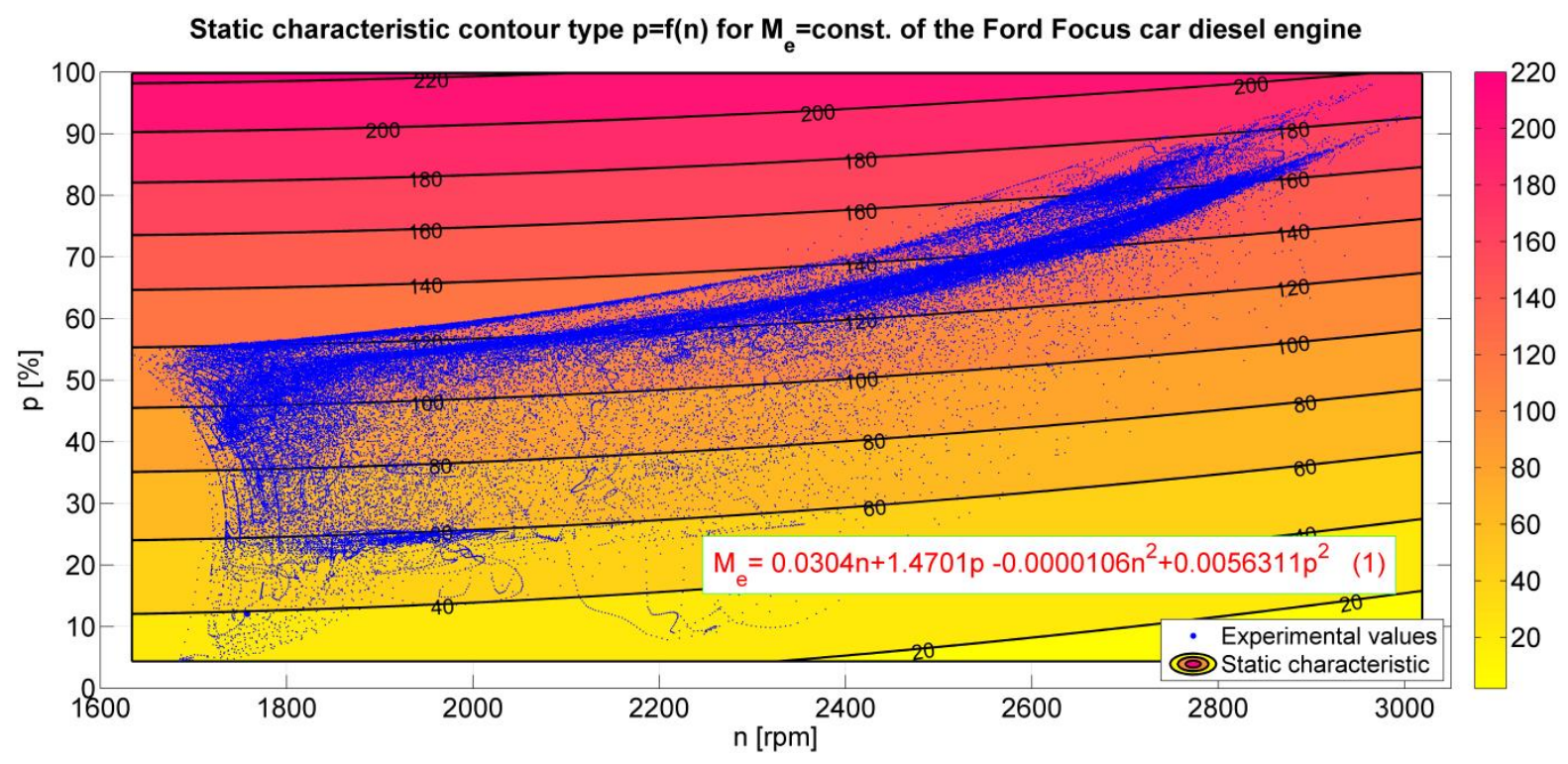

Fig. 15 Mathematical model of form $M_{e}=\mathrm{f}(\mathrm{n}, p)$, contour representation

\section{CONCLUSION}

Experimental research conducted with an electronically controlled diesel engine benefits from the existence of built-in sensors and actuators, an on-board computer and specialized equipment for data acquisition and storage.

Based on the data purchased from the on-board computer, the operation of the engine at different loads and speeds is analyzed. Experiments have shown that the engine runs predominantly at partial loads and very little at full load.

Also, based on experimental data can be established customized or generalized mathematical models, which can be used to control the engine and to optimize its performance.

\section{REFERENCES}

[1]. J. Chauvin ș. a., Modeling and control of a Diesel HCCI engine, Institut Francais du Petrol, 2017, Fifth IFAC Symposium on Advances in Automotive Control, Seascape Resort : United States (2007)". DOI : 10.3182/20070820-3-US-2918.00064

[2]. Li. Cheng, Transient modeling of a Diesel engine and air-path control. Doctoral Thesis, University of Sussex, 2015. http://sro.sussex.ac.uk/id/eprint/55340/

[3]. M. Huang ș.a., Toward Real-Time Automotive Model Predictive Control: A Perspective from a Diesel Air Path Control Development, 2018 , DOI: $10.23919 /$ ACC.2018.8431407

[4]. R. Islam, S. Hasan, Integration of Mechanical Systems with IoT, International Advanced Research Journal in Science, Engineering and Technology (IARJSET), Vol. 8, Issue 1, January 2021, pag. 43-50

[5]. A. Mehmood, Modeling, simulation and robust control of an electro-pneumatic actuator for VGT., These de Doctorat, Universite de technologie Belfort-Montbeliard, 2013. https://tel.archives-ouvertes.fr/file/index/docid/827445/

[6]. A. Shamdani ș.a., Air intake modeling with fuzzy AFR control of a turbo- charged Diesel engine, International Journal Vehicle Systems Modelling and Testing, Vol. 3, No. 1/2, 2008, page 114-138. https://doi.org/10.1504/IJVSMT.2008.020621

[7]. J. Singh, A review on system in Diesel engines, International Journal of Advanced Technology in Engineering and Science, vol. 4, mai 2016. https://www.ijates.com/images/short_pdf/1464436108_161ijates.pdf

[8]. X.T. Tran, Modelling and simulation of electronically controlled Diesel injectors, Thesis, 2003, Sydney. https://trove.nla.gov.au/work/3755191.

[9]. R. Vilău, I. Lespezeanu, M. Singureanu, Considerations regarding the influence of inappropriate electronic throttle unit operation on pollutant emissions of internal combustion engines, 5th International Scientific Conference SEA-CONF 2019, IOP Conf. Series: Journal of Physics: Conf. Series 1297 (2019) 012032, IOP Publishing, doi:10.1088/1742-6596/1297/1/012032

[10]. L. Barothi, D. Voicu, R.-M. Stoica, M. Singureanu, Recording of parameters characteristic to engine and vehicle in order to validate a simulation model for fuel consumption, 5th International Scientific Conference SEA-CONF 2019, 17-18 May 2019, Mircea cel Batran Naval Academy, Constanta, Romania, IOP Conf. Series: Journal of Physics: Conf. Series 1297 (2019) 012030 IOP Publishing, doi:10.1088/1742$6596 / 1297 / 1 / 012030$ 